\title{
A Novel Deep Intronic Mutation Introducing a Cryptic Exon Causing Neurofibromatosis Type 1 in a Family with Highly Variable Phenotypes: A Case Study
}

\author{
Eva Kathrine Svaasand ${ }^{1}$, Lars Fredrik Engebretsen ${ }^{2}$, Trond Ludvigsen ${ }^{1}$, Wenche Brechan ${ }^{1}$ and Wenche Sjursen ${ }^{1,3}$ \\ ${ }^{1}$ Department of Pathology and Medical Genetics, St. Olavs University Hospital, Trondheim, Norway \\ ${ }^{2}$ Centre for Genetics and Molecular Medicine, Haukeland University Hospital, Bergen, Norway \\ ${ }^{3}$ Department of Laboratory Medicine Children's and Women's Health, Norwegian University of Science and Technology, Trondheim, Norway
}

\begin{abstract}
Neurofibromatosis type 1 (NF1) is a common dominant inherited disorder with highly variable expressivity. Genetic testing for this condition has been more available the last decade. Here we present a case report of a NF1 family including seven affected family members, some of them with a very severe phenotype. When searching for a causative mutation in the NF1 gene, no mutation was found at DNA level. However, a misspliced transcript including a subsequence of intron 3 appeared when screening RNA. The underlying cause at DNA level was determined to be a deep intronic variant $(\mathrm{c} .288+1137 \mathrm{C}>\mathrm{T}$ ). This intronic point mutation creates a new splice site causing the insertion of a cryptic exon (r.288_289ins288+1018_1135), leading to reading frameshift at the protein level. Deep intronic mutations introducing a cryptic exon are known to be a cause of NF1, and we reviewed the literature to evaluate how common this mutation is in NF1 syndrome. We found 20 different deep intronic NF1 splice mutations, including the one found in the present study. In conclusion, this case illustrates the value of RNA analysis to detect the cause of genetic diseases, and we decided to use RNA based mutation screening as standard procedure for NF1 genetic testing in our laboratory.
\end{abstract}

Keywords: NF1; Splice mutation; Splice site predictor; Consensus splice site; Cryptic exon; Deep intronic mutations

Abbreviations: NF1: Neurofibromatosis Type 1; MPNSTs: Malignant Peripheral Nerve Sheath Tumours; MLPA: Multiplex Ligation-Dependent Probe Amplification

\section{Introduction}

Neurofibromatosis type 1 (NF1), also called von Recklinghausen disease (OMIM \# 162200), is one of the most common dominant inherited disorders; the worldwide incidence is $1 / 3500$ [1-3]. The signature of NF1 is the development of benign neurofibromas, i.e. benign peripheral nerve sheath tumours, in addition to multiple caféau-lait spots and Lisch nodules in the eye [3]. Individuals with NF1 also have increased risk to develop malignant tumours, among which malignant peripheral nerve sheath tumours (MPNSTs) are the most severe. The penetrance of NF1 is reported to be $100 \%$. However, the clinical manifestations of NF1 shows highly variable expression, i.e. the severity of disease varies among affected individuals within the same family and from one family to another [2].

Obvious genotype-phenotype correlations are not common in NF1 $[1,4,5]$. However, two clear clinically important genotype-phenotype correlations are revealed so far; one concerns patients with particularly severe forms of NF1 that carry large deletions encompassing the entire NF1 gene $[3,6,7]$ and the other concerns patients carrying small mutations such as a 3-bp inframe deletion of the NF1 gene [8]. Genetic modifiers that lie outside the NF1 gene appear to account for a large fraction of the symptomatic variability seen in NF1 $[3,8]$.

In up to $95 \%$ of cases, NF1 clinical diagnosis can be made through straightforward clinical evaluation fulfilling a set of clinical criteria $[9,10]$. The diagnostic criteria are met in a patient who has two or more of the following main characteristics: six or more café-au-lait spots, neurofibromas, skinfold freckling, optic glioma, iris Lisch nodules, distinctive bone lesions and first degree relatives with NF1 [11].

The NF1 gene is a tumour suppressor gene whose protein neurofibromin down regulates Ras-GTP levels in Ras/MAPK/AP-1 pathway [12].
Genetic testing can confirm the diagnosis in questionable cases, and is required for prenatal or preimplantation diagnosis [13]. Further, it is important to determine the genetic cause of NF1 in families, in order to do predictive testing and to give family members healthcare follow-ups. The NF1 gene has a high mutation rate, and about half of the NF1 cases are sporadic (de novo NF1 mutations) [13,14].

Mutation detection in the NF1 gene is complex due to its large size (60 exons, whereas three of them are alternatively spliced), the existence of several pseudogenes and the lack of clustering of the mutations [15]. There are no clear mutation hotspots and the spectrum of mutations is very diverse, ranging from microdeletions affecting the entire NF1 gene to minor lesions that include a high proportion of splicing mutations [16].

In this study we report on a family with several affected individuals with strongly variable phenotypes. They were referred to the outpatient clinic several years before we succeed to find the genetic cause of their disease. It was first after we introduced RNA based analysis that their mutation in the NF1 gene was found.

\section{Case presentation}

The family includes seven affected members over three generations (I- III) as shown in Figure 1. Family members were referred to genetic outpatient clinics where they received genetic counselling. They gave written consents for mutation screening and for publication of the results. In generation I, the father had clinical von Recklinghausen diagnosis,

*Corresponding author: Wenche Sjursen, Department of Pathology and Medical Genetics, St. Olavs University Hospital, Trondheim, Norway, Tel: +4772573530l E-mail: wenche.sjursen@ntnu.no

Received July 15, 2015; Accepted July 28, 2015; Published July 30, 2015

Citation: Svaasand EK, Engebretsen LF, Ludvigsen T, Brechan W, Sjursen W (2015) A Novel Deep Intronic Mutation Introducing a Cryptic Exon Causing Neurofibromatosis Type 1 in a Family with Highly Variable Phenotypes: A Case Study. Hereditary Genet 4: 152. doi:10.4172/2161-1041.1000152

Copyright: (C) 2015 Svaasand EK, et al. This is an open-access article distributed under the terms of the Creative Commons Attribution License, which permits unrestricted use, distribution, and reproduction in any medium, provided the original author and source are credited. 
Citation: Svaasand EK, Engebretsen LF, Ludvigsen T, Brechan W, Sjursen W (2015) A Novel Deep Intronic Mutation Introducing a Cryptic Exon Causing Neurofibromatosis Type 1 in a Family with Highly Variable Phenotypes: A Case Study. Hereditary Genet 4: 152. doi:10.4172/21611041.1000152

Page 2 of 5

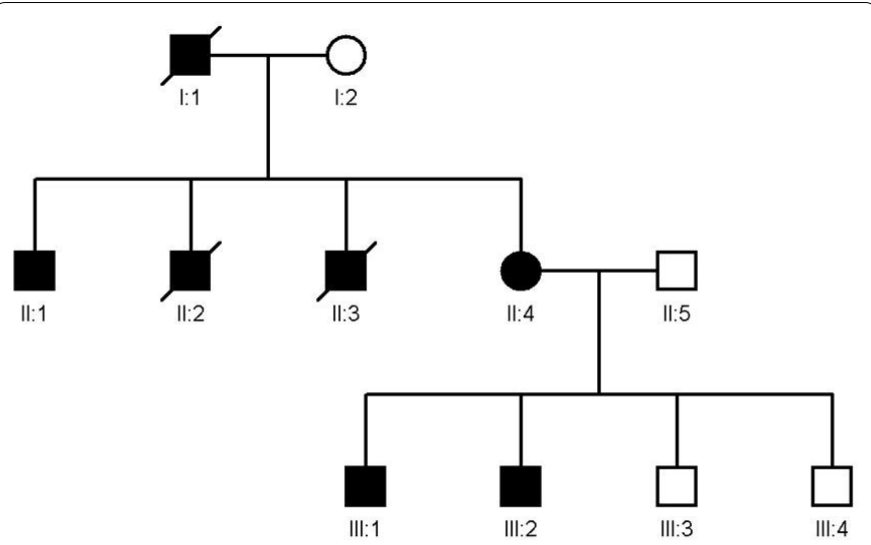

Figure 1: Pedigree of the affected family.

The solid colour represents affected individuals. In the first generation there is a deceased father with clinical NF1 diagnosis $(\mathrm{I}: 1)$ and a healthy mother $(\mathrm{I}: 2)$. All of the four children in the second generation had NF1: one lightly affected son (II:1) and one daughter (II:4), and two severely affected sons who are both deceased (II:2 and II:3). The daughter has four children which comprises the third generation: two of her four sons are affected with NF1 based on clinical observations (III:1 and III:2)

with numerous café-au-lait spots and cutaneous neurofibromas. He died at age 62 before genetic testing was available. In the second generation, all four siblings had NF1, which has been confirmed by genetic testing. The first (II.1) sibling is mildly affected, with numerous café-au-lait spots, cutaneous neurofibromas and freckling in the axillaries. He is functioning well and holding up a full time job. The now deceased son (II.2) was severely affected with numerous neurofibromas, the first surgically removed at age 11 . He had cauda equina syndrome, sarcoma vesica, epilepsy from age 30 and reduced hearing. As a child, he underwent cardiac surgery for atrial septal defect. He died at age 46 . The other deceased sibling (II.3) was also severely affected, with plexiform neurofibromas both in the head and extracranially. He had several tumours (cervical spine, craniocervical transition and intraspinally), and epilepsy. He was moderately retarded, lacked language, and died at age 39 . The lightly affected daughter (II.4) has café-au-lait spots and no neurological symptoms. However, magnetic resonance imaging of head and spine revealed small neurofibromas, and she had a benign colloid nodule in the thyroid gland. Two of her four sons are affected with NF1. The oldest was diagnosed with NF1 as an infant, with caféau-lait spots, Lisch nodules, and neurofibromas. The other one was moderately affected with cutaneous symptoms. Genetic testing has not been performed for any of her children.

\section{Methods}

\section{DNA analysis}

The entire NF1 gene (60 coding exons) including two exons with tissue specific expression was screened by High Resolution Melt mutation detection analysis (Corbett Rotor Gene 6000, Qiagen) and Sanger sequencing using Big Dye technology (ABI 3130xl Genetic analyser, Applied Biosystems) according to standard protocols and as reported previously [17]. As part of the screening process, Multiplex Ligation-dependent Probe Amplification (MLPA; Salsa MLPA kit P081-B1/P082-B1 NF1, from MRC-Holland) was applied in order to detect aberrant copy numbers of genomic DNA, such as large gene duplications or deletions. DNA PCR primers were designed to amplify the region of intron 3 where a mutation was suspected based on the sequence of the intron sequence insert.

\section{RNA analysis}

The PAXgene ${ }^{\text {ma }}$ blood-tube system (PreAnalytiX) was used to preserve the RNA profile of the blood samples. RNA isolation was conducted following standard protocols using Paxgene ${ }^{\text {mit }}$ Blood RNA kit (PreAnalytiX). The cDNA was synthesised from the total RNA using random primers, following the standard protocol using SuperScript III Reverse Transcriptase (Invitrogen). In order to cover the entire cDNA, 21 overlapping PCR reactions were sequenced using Taq Advanced polymerase (5 Prime). Primers were adapted from Thompson et al. [18] sequencing was performed with Big Dye Terminator Sequencing Chemistry and ABI3130xl, and the analyse software was SeqScape (Applied Biosystems). The fragment containing the aberrant transcript, Fragment 1, was amplified with a forward primer located in the 5'UTR region and a reverse primer located in exon 7.

\section{Nomenclature and software predictions}

The nomenclature for the mutation at the DNA and RNA level and the predicted protein was determined according to the guidelines of the Human Genome Variation Society [19]. NCBI exon numbering, and the NF1 mRNA NCBI Ref Seq. NM_000267.3 were applied. The A of the transcription start codon was defined as nucleotide number 1.

Splice site prediction by neural network (SSPN) allows searching for potential splice sites in long sequence stretches (www.fruitfly.org/ seq_tools/splice.html). Alamut (version 2.3, Interactive Biosoftware), which include several other splice prediction programs, were also applied.

\section{Literature search}

Available literature and databases were searched to see how common deep intronic splice mutations are in NF1. These variants are defined as "mutations that alter a single nucleotide often within very large introns, creating de novo 5' or 3' intronic splice sites that is used in conjunction with an already available intronic "partner" cryptic splice site leading to inclusion of a cryptic exon" [20]. Search words were NF1, deep intron/intronic variants/mutations, new splice sites and cryptic exons. Four databases were searched ( PubMed, Google Scholar, Leiden Open Variation Database

(https://grenada.lumc.nl/LOVD2/mendelian_genes/variants. php?select_db=NF1\&action=view_unique) and HGMD (The Human Gene Mutation Database)). The results included were those variants that have been shown to alter splicing and are located more than 50 nucleotides from the 5' or 3' end of exons.

\section{Results}

No pathogenic NF1 mutation was initially detected in genomic DNA from two of the affected siblings. However, the clinical diagnosis NF1 was fulfilled in the affected family members. We therefore established cDNA analysis based on PAXgene ${ }^{\text {Tx }}$ blood samples.

An aberrant transcript including a cryptic exon was discovered, r.288_289ins288+1018_1135. The cryptic exon was found to be a subsequence of 118 nucleotides from intron 3 (Figure 2D). The insertion introduces a frame shift in the transcript, leading to a stop codon in exon 4 . The underlying cause at DNA level was determined to be a deep intronic variant c. $288+1137 \mathrm{C}>\mathrm{T}$ (Figure 2B).

The cDNA analysis was performed in samples from two of the affected siblings in generation II, one with milder symptoms (II.1) and one severely affected (II.2). This DNA variant was detected in all affected family members in generation I and II, but not in those without 
Citation: Svaasand EK, Engebretsen LF, Ludvigsen T, Brechan W, Sjursen W (2015) A Novel Deep Intronic Mutation Introducing a Cryptic Exon Causing Neurofibromatosis Type 1 in a Family with Highly Variable Phenotypes: A Case Study. Hereditary Genet 4: 152. doi:10.4172/21611041.1000152

Page 3 of 5

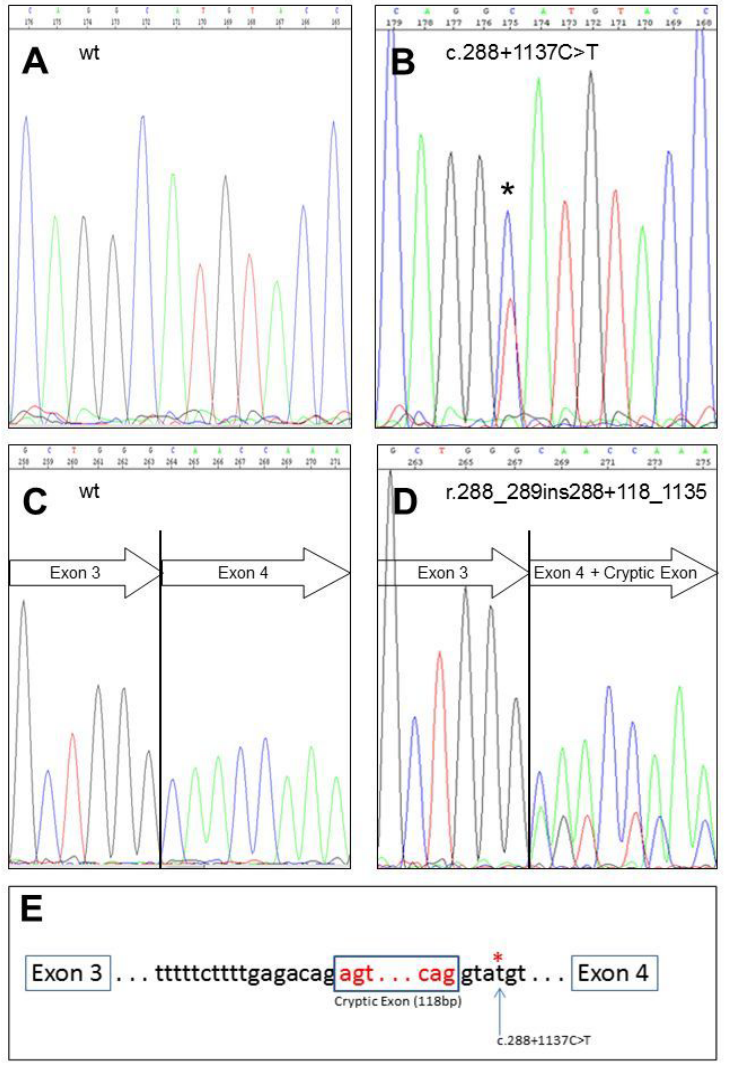

Figure 2: NF1 sequencing results of DNA (A and $B)$ and $C D N A(C$ and $D)$, showing the mutated sequence $(B)$ causing aberrant splicing and the subsequent insertion of a cryptic exon (D), in contrast to the sequence from an unaffected family member ( $A$ and $C$ ). E illustrates the localisation of the mutation deep inside intron 3 , including the insertion of a cryptic exon (118bp) between exon 3 and 4 . a NF1 diagnosis. No reports of polymorphisms in the NF1 c.288+1137 position were found, the variant was not reported in the dbSNP or 1000 Genomes databases, and the variant was not detected in 100 alleles in samples from blood donors. In silico splice site prediction showed that the mutated sequence results in a donor site prediction score of 1.00 (max output) when analysed with SSPN, while the same site did not produce any score when the normal sequence was applied. Other splice site prediction tools also predicted a new splice donor site, MaxEntScan 9.8 (span 0-12) and Human Splicing Finder 91.2 (span 0-100). The introduction of the cryptic exon is illustrated in Figure $2 \mathrm{E}$.

The DNA intronic variant c. $288+1137 \mathrm{C}>\mathrm{T}$ was concluded to be the genetic cause of NF1 in this family. This provided a predictive tool for the other family members.

NF1 mutation testing has been performed in our laboratory since 2006, initially based on screening at DNA level (Sanger sequencing and dHPLC). The cDNA analysis based on PAXgene ${ }^{\mathrm{m} m}$ system was introduced later. Since 2013 our mutation screening method is based on RNA extracted from cultured lymphocytes treated with the translation inhibitor puromycin to prevent degradation of transcripts with premature stop codon by Nonsense Mediated mRNA Decay [21]. Deep intronic splice mutations are missed when traditional DNA based screening techniques are applied [21]. As the advantages of RNA based screening is becoming apparent and is applied, these mutations are expected to be increasingly reported in the literature. Literature search revealed 19 different deep intronic splice mutations reported so far, totally 20 when including the one found in the present study. The results with references are shown in Table 1 [4,16,20,22-32].

Recently we detected a second deep intronic variant in another family $(c .5749+332 \mathrm{~A}>\mathrm{G})$. This variant has been published by others and is included in Table $1[16,22,30,33]$.

\begin{tabular}{|c|c|c|c|c|}
\hline Mutation & mRNA effect & Protein & LOVD NF1 ID & Ref \\
\hline c.60+9032_60+9036del5 & r.60_61ins60+8962_60+9030 & p.GIn20_Leu21ins23 & 01129 & [22] \\
\hline c.61-7486G>T & r.60-61ins61-7565_61-7492 & p.GIn20_Leu21insThr* & _01132 & [22] \\
\hline c. $288+2025 T>G$ & r.288_289ins288+1917_288+2024 & p.Gln $97^{*}$ & ND & [23] \\
\hline c. $288+1137 \mathrm{C}>\mathrm{T}$ & r.288_289ins288+1018_288+1135 & p. Gln97Serfs*49 & ND & This study \\
\hline c. $888+651 \mathrm{~T}>\mathrm{A} \S$ & r. $888 \_889$ ins $888+653$ _888+784ins & p.Lys297_Val2818delinsGluLysTyrSer* & ND & [20] \\
\hline c. $888+789 A>G$ & r.888_889ins888+710_888+784 & p.Lys297fs & _01154 & [22] \\
\hline c. $888+10312 A>G$ & r.888_889ins888+10233_888+10311 & p.Lys297fs & _01155 & [22] \\
\hline c. $889-942 \mathrm{G}>\mathrm{T}$ & r.888_889ins889-931_889-873 & p.Lys297Valfs*11 & ND & [23] \\
\hline c. $1062+113 A>G$ & r.1062_1063ins113 & p.Asn355fs & _01620 & Italy: Milano \\
\hline c. $1260+1604 A>G$ & r.1260_1261ins $1260+1605 \_1260+1646$ & p.Asn420_Ser421insLeuThrThr* & _00035 & {$[22,24]$} \\
\hline c. $1393-592 A>G$ & r.1392_1393ins1393-671_1393-596 & p.Ser465Alafs*9 & _ 01179 & {$[22,23]$} \\
\hline c. $1527+1159 \mathrm{C}>\mathrm{T}$ & r.1527_1528ins1527+1103_1527+1157 & p.Asn510Aspfs ${ }^{*} 8$ & ND & {$[16,23,27]$} \\
\hline c. $1642-449 A>G$ & Not described & Not described & ND & [28] \\
\hline c. $1721+542 A>G$ & r.1721_1722ins $1721+362 \_1721+537$ & p.Ser574_Ser575insPhePhe GluLeu* & _01186 & [22] \\
\hline c. $3198-314 G>A$ & $\begin{array}{c}\text { r.3197-3198ins3198-214-3198-312, sr.3197- } \\
\text { 3198ins3198-245-3198-312 \# }\end{array}$ & p.Asp1067TrpfsX7 & ND & [29] \\
\hline c. $4110+945 A>G$ & r.4110_4111ins 105 & p.GIn1370_Val1371ins $35^{\star} 27$ & ND & [25] \\
\hline c. $4173+278 A>G$ a & r.4173_4174ins4173+279_4173+358 & p.Val1392llefs $* 9$ & ND & [26] \\
\hline c. $5749+332 A>G$ & r.5749_5750ins5749+155_5749+331 & p.Ser1917Argfs ${ }^{\star} 12$ & _01315 & {$[16,22,30,33$, this study $]$} \\
\hline c. $5750-279 A>G$ & r.5749_5750ins5750_278_5750-108 & p.Ser1917delins58 & ND & {$[31,32]$} \\
\hline c. $7908-321 C>G$ & r.7907_7908ins7908-322_7908-391 & p.His2637SerfsX2 & ND & {$[4,23]$} \\
\hline
\end{tabular}

Table 1: NF1 Deep intron variants found in the literature. 
Citation: Svaasand EK, Engebretsen LF, Ludvigsen T, Brechan W, Sjursen W (2015) A Novel Deep Intronic Mutation Introducing a Cryptic Exon Causing Neurofibromatosis Type 1 in a Family with Highly Variable Phenotypes: A Case Study. Hereditary Genet 4: 152. doi:10.4172/2161 1041.1000152

Page 4 of 5

\section{Discussion}

This case study illustrates the extensive effects a deep intronic NF1 mutation can have on the individual members in a family. Further, it emphasizes the importance of applying RNA analysis in the search of a molecular explanation for clinical NF1 phenotypes.

The NF1 mutation found in the family was a deep intronic variant in a position that has not been described previously. By performing extensive literature search our aim was to focus on this group of mutations in the NF1 gene. The search shows that deep intronic mutations are not extremely frequent. Nevertheless, they are just as important to reveal as exonic mutations and well known splice site flanking mutations, since their effects are equally significant in causing serious disease. One must also keep in mind that this type of mutation most likely is underreported in the literature, since RNA analysis is relatively recently applied in routine diagnostics.

It is estimated that splice mutations account for a substantial part of NF1 mutations. In a cohort of 97 Austrian NF1 patients it was found that splicing mutations represent the largest group of NF1 gene alterations (38\%). [16] Another study based on 2900 unrelated patients found 29\% splicing mutations in NF1. Fifty seven percent of these reside outside the conserved splice donor and acceptor, and $10 \%$ of them belong to deep intronic splice mutations, i.e.2-3\% of all NF1 mutations [21]. Similar frequencies were found in a French cohort [22]. They detected 114 intronic splice mutations out of 546 mutations ( $21 \%)$, and among these 13 were deep intronic mutations $(2.4 \%)$. At our laboratory, we have detected disease causing NF1 mutations in 246 index patient samples analysed in the period 2006-2014. Thus, the number of deep intronic mutations found in our laboratory (about $1 \%$ ) correlates with the number reported in the literature. As reported by others [11], our mutation detection rate in NF1 has increased by changing the screening method from DNA-based to RNA-based screening. Besides increasing the detection rate, the cDNA based method is faster and more labourand cost-effective as compared to a DNA-based method.

The median life expectancy of individuals with NF1 is approximately eight years shorter than in the general population [34,35]. In the present family two members were severely affected and died at age 39 and 46 years, respectively, far below normal life expectancy. Malignancy and vasculopathy are reported to be the most important causes of early death in individuals with NF1 [36-38]. The two severely affected members in the present family had intraspinal neurofibromas, which caused reduced muscle strength, wheelchair dependence, weakened skeletons, orthopedic problems and fractures. They died of complications after orthopedic surgery. The two other siblings in generation II are managing quite well. They are both in their forties and are much less affected. This illustrates the wide variety in expression which is reported for NF1 [2]. The reason for the extreme clinical variability of NF1 is unclear although the timing and frequency of second hit events in specific cell types likely will contribute significantly. Statistical analysis of the NF1 phenotype within and between families shows that the NF1 mutant allele itself accounts for only a small fraction of phenotypic variation [39]. Further, it is suggested that genetic modifiers not linked to the NF1 locus and differences in expression of the normal NF1 allele contribute to the variable expressivity of the disease [39-42]. A role for microRNAs in the development of MPNST has been suggested [43]. Thus differences in microRNA expression may partly be one of the contributions to why some NF1 patients get malignant tumours while other only get benign tumours.

\section{Conclusions}

In this case study we have described a NF1 family with great variability in phenotype of affected members, ranging from early death to normal functionality. The underlying genetic cause was found to be a new single base substitution deep in intron, causing altered splicing. Thus, we can offer predictive testing for family members. The case report also emphasizes the importance of using the right methods to find the causative NF1 alteration in patients clinically fulfilling NF1 criteria.

\section{Authors' contributions}

ES, WB and WS performed the laboratory testing, and LFE and TL the genetic counselling and the clinical assessments. All authors contributed to the writing of the paper.

\section{Acknowledgement}

We like to thank the family members who contributed to this study. We also want to acknowledge Dr. Christa Schmidt for proof reading of the article.

\section{References}

1. De Luca A, Bottillo I, Dasdia MC, Morella A, Lanari V, Bernardini L, Divona L, Giustini S, Sinibaldi L, Novelli A et al: Deletions of NF1 gene and exons detected by multiplex ligation-dependent probe amplification. Journal of medical genetics 2007, 44(12):800-808.

2. Williams VC, Lucas J, Babcock MA, Gutmann DH, Korf B, Maria BL: Neurofibromatosis type 1 revisited. Pediatrics 2009, 123(1):124-133.

3. McClatchey Al: Neurofibromatosis. Annual review of pathology 2007, 2:191216.

4. Ars E, Kruyer H, Morell M, Pros E, Serra E, Ravella A, Estivill X, Lazaro C: Recurrent mutations in the NF1 gene are common among neurofibromatosis type 1 patients. Journal of medical genetics 2003, 40(6):e82.

5. Upadhyaya M, Cooper DN: Neurofibromatosis Type 1 Molecular and Cellular Biology, Berlin, Heidelberg: Springer Berlin Heidelberg: Springer 2012.

6. Leppig KA, Kaplan P, Viskochil D, Weaver M, Ortenberg J, Stephens K Familial neurofibromatosis 1 microdeletions: cosegregation with distinct facial phenotype and early onset of cutaneous neurofibromata. American journal of medical genetics 1997, 73(2):197-204.

7. Kayes LM, Burke W, Riccardi VM, Bennett R, Ehrlich $P$, Rubenstein A Stephens K: Deletions spanning the neurofibromatosis 1 gene: identification and phenotype of five patients. American journal of human genetics 1994 54(3):424-436

8. Upadhyaya M, Huson SM, Davies M, Thomas N, Chuzhanova N, Giovannin S, Evans DG, Howard E, Kerr B, Griffiths $S$ et al: An absence of cutaneous neurofibromas associated with a 3-bp inframe deletion in exon 17 of the NF1 gene (c.2970-2972 delAAT): evidence of a clinically significant NF1 genotypephenotype correlation. American journal of human genetics 2007, 80(1):140-151.

9. Neurofibromatosis. Conference statement. National Institutes of Health Consensus Development Conference. Archives of neurology 1988, 45(5):575-578.

10. Gutmann DH, Aylsworth A, Carey JC, Korf B, Marks J, Pyeritz RE, Rubenstein A, Viskochil D: The diagnostic evaluation and multidisciplinary management of neurofibromatosis 1 and neurofibromatosis 2. JAMA : the journal of the American Medical Association 1997, 278(1):51-57.

11. Jett K, Friedman JM: Clinical and genetic aspects of neurofibromatosis 1 Genetics in medicine : official journal of the American College of Medical Genetics 2010, 12(1):1-11.

12. Brundage ME, Tandon P, Eaves DW, Williams JP, Miller SJ, Hennigan RH, Jegga A, Cripe TP, Ratner N: MAF mediates crosstalk between Ras-MAPK and mTOR signaling in NF1. Oncogene 2014.

13. Shen MH, Harper PS, Upadhyaya M: Molecular genetics of neurofibromatosis type 1 (NF1). Journal of medical genetics 1996, 33(1):2-17

14. Boyd KP, Korf BR, Theos A: Neurofibromatosis type 1. Journal of the American Academy of Dermatology 2009, 61(1):1-14; quiz 15-16.

15. Messiaen LM, Callens T, Mortier G, Beysen D, Vandenbroucke I, Van Roy N Speleman F, Paepe AD: Exhaustive mutation analysis of the NF1 gene allows 
Citation: Svaasand EK, Engebretsen LF, Ludvigsen T, Brechan W, Sjursen W (2015) A Novel Deep Intronic Mutation Introducing a Cryptic Exon Causing Neurofibromatosis Type 1 in a Family with Highly Variable Phenotypes: A Case Study. Hereditary Genet 4: 152. doi:10.4172/2161 1041.1000152

Page 5 of 5

identification of $95 \%$ of mutations and reveals a high frequency of unusual splicing defects. Human mutation 2000, 15(6):541-555.

16. Wimmer K, Roca X, Beiglbock H, Callens T, Etzler J, Rao AR, Krainer AR, Fonatsch C, Messiaen L: Extensive in silico analysis of NF1 splicing defects uncovers determinants for splicing outcome upon 5' splice-site disruption. Human mutation 2007, 28(6):599-612.

17. Sjursen W, Halvorsen H, Hofsli E, Bachke S, Berge A, Engebretsen LF, Falkmer SE, Falkmer UG, Varhaug JE: Mutation screening in a Norwegian cohort with pheochromocytoma. Familial cancer 2013, 12(3):529-535.

18. Thomson SA, Wallace MR: RT-PCR splicing analysis of the NF1 open reading frame. Human genetics 2002, 110(5):495-502.

19. den Dunnen JT, Antonarakis SE: Nomenclature for the description of human sequence variations. Human genetics 2001, 109(1):121-124.

20. Messiaen LM, Wimmer, K.: NF1 Mutational Specrum. In: Neurofibromatoses. Edited by Kaufmann D, vol. 16. Basel: Karger; 2008: 63-77.

21. Messiaen L, Wimmer, K.: Mutation Analysis of the NF1 Gene by cDNAbased Sequencing of the Coding Region. In: Advances in Neurofibromatosis Research. Edited by Cunha KSGaG, M.: Nova Science Publishers, Inc; 2011.

22. Sabbagh A, Pasmant E, Imbard A, Luscan A, Soares $M$, Blanche $H$, Laurendeau I, Ferkal S, Vidaud M, Pinson $S$ et al: NF1 molecular characterization and neurofibromatosis type I genotype-phenotype correlation: the French experience. Human mutation 2013, 34(11):1510-1518.

23. Pros E, Gomez C, Martin T, Fabregas P, Serra E, Lazaro C: Nature and mRNA effect of 282 different NF1 point mutations: focus on splicing alterations. Human mutation 2008, 29(9):E173-193

24. Valero MC, Martin Y, Hernandez-Imaz E, Marina Hernandez A, Melean G Valero AM, Javier Rodriguez-Alvarez F, Telleria D, Hernandez-Chico C: A highly sensitive genetic protocol to detect NF1 mutations. J Mol Diagn 2011 , 13(2):113-122

25. Brinckmann A, Mischung C, Bassmann I, Kuhnisch J, Schuelke M, Tinschert S Nurnberg P: Detection of novel NF1 mutations and rapid mutation prescreening with Pyrosequencing. Electrophoresis 2007, 28(23):4295-4301.

26. Kannu P, Nour M, Irving M, Xie J, Loder D, Lai J, Islam O, MacKenzie J, Messiaen L: Paraspinal ganglioneuroma in the proband of a large family with mild cutaneous manifestations of NF1, carrying a deep NF1 intronic mutation. Clin Genet 2013, 83(2):191-194.

27. Spits C, De Rycke M, Van Ranst N, Joris H, Verpoest W, Lissens W, Devroey $P$ Van Steirteghem A, Liebaers I, Sermon K: Preimplantation genetic diagnosis for neurofibromatosis type 1. Mol Hum Reprod 2005, 11(5):381-387.

28. Jeong SY, Park SJ, Kim HJ: The spectrum of NF1 mutations in Korean patients with neurofibromatosis type 1. J Korean Med Sci 2006, 21(1):107-112.

29. Fernandez-Rodriguez J, Castellsague J, Benito L, Benavente Y, Capella G, Blanco I, Serra E, Lazaro C: A mild neurofibromatosis type 1 phenotype produced by the combination of the benign nature of a leaky NF1-splice mutation and the presence of a complex mosaicism. Human mutation 2011 , 32(7):705-709.
30. Perrin G, Morris MA, Antonarakis SE, Boltshauser E, Hutter P: Two nove mutations affecting mRNA splicing of the neurofibromatosis type 1 (NF1) gene. Human mutation 1996, 7(2):172-175.

31. Osborn MJ, Upadhyaya M: Evaluation of the protein truncation test and mutation detection in the NF1 gene: mutational analysis of 15 known and 40 unknown mutations. Human genetics 1999, 105(4):327-332.

32. Raponi M, Upadhyaya M, Baralle D: Functional splicing assay shows a pathogenic intronic mutation in neurofibromatosis type 1 (NF1) due to intronic sequence exonization. Human mutation 2006, 27(3):294-295

33. Ars E, Serra E, Garcia J, Kruyer H, Gaona A, Lazaro C, Estivill X: Mutations affecting mRNA splicing are the most common molecular defects in patients with neurofibromatosis type 1. Human molecular genetics 2000, 9(2):237-247.

34. Evans DG, O'Hara C, Wilding A, Ingham SL, Howard E, Dawson J, Moran A Scott-Kitching V, Holt F, Huson SM: Mortality in neurofibromatosis 1: in North West England: an assessment of actuarial survival in a region of the UK since 1989. European journal of human genetics : EJHG 2011, 19(11):1187-1191.

35. Wilding A, Ingham SL, Lalloo F, Clancy T, Huson SM, Moran A, Evans DG: Life expectancy in hereditary cancer predisposing diseases: an observational study. Journal of medical genetics 2012, 49(4):264-269.

36. Masocco M, Kodra Y, Vichi M, Conti S, Kanieff M, Pace M, Frova L, Taruscio D: Mortality associated with neurofibromatosis type 1: a study based on Italian death certificates (1995-2006). Orphanet journal of rare diseases 2011, 6:11.

37. Rasmussen SA, Yang Q, Friedman JM: Mortality in neurofibromatosis 1: an analysis using U.S. death certificates. American journal of human genetics 2001, 68(5):1110-1118

38. Zoller M, Rembeck B, Akesson HO, Angervall L: Life expectancy, mortality and prognostic factors in neurofibromatosis type 1. A twelve-year follow-up of an epidemiological study in Goteborg, Sweden. Acta dermato-venereologica 1995, 75(2):136-140.

39. Sabbagh A, Pasmant E, Laurendeau I, Parfait B, Barbarot S, Guillot B Combemale P, Ferkal S, Vidaud M, Aubourg P et al: Unravelling the genetic basis of variable clinical expression in neurofibromatosis 1 . Human molecular genetics 2009, 18(15):2768-2778

40. Easton DF, Ponder MA, Huson SM, Ponder BA: An analysis of variation in expression of neurofibromatosis (NF) type 1 (NF1): evidence for modifying genes. American journal of human genetics 1993, 53(2):305-313.

41. Szudek J, Joe H, Friedman JM: Analysis of intrafamilial phenotypic variation in neurofibromatosis 1 (NF1). Genetic epidemiology 2002, 23(2):150-164.

42. Jentarra GM, Rice SG, Olfers S, Rajan C, Saffen DM, Narayanan V: Skewed allele-specific expression of the NF1 gene in normal subjects: a possible mechanism for phenotypic variability in neurofibromatosis type 1 . Journal of child neurology 2012, 27(6):695-702.

43. Sedani A, Cooper DN, Upadhyaya M: An emerging role for microRNAs in NF tumorigenesis. Human genomics 2012, 6:23. 